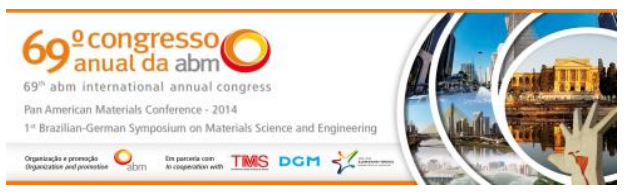

Tema: Mecânica de fratura e integridade estrutural

\title{
INVESTIGAÇÃO DOS MÉTODOS DE DETERMINAÇÃO DA TEMPERATURA DE TRANSIÇÃO DÚCTIL-FRÁGIL (TTDF) UTILIZANDO ENSAIO DE IMPACTO CHARPY*
}

Kátia Cristina Gouveia ${ }^{1}$ Rodrigo Magnabosco ${ }^{2}$

\section{Resumo}

O objetivo deste trabalho foi determinar a TTDF do aço ASTM A36 com diferentes graus de encruamento após ensaios de impacto Charpy, sob diversas metodologias. Não se notaram diferenças no comportamento do material quando se avaliam os valores de TTDF obtidos pela medição da expansão lateral dos corpos de prova, nem considerando o valor da TTDF na qual o material apresenta $50 \%$ de fratura frágil, usando as metodologias de avaliação visual das faces de fratura dos corpos de prova, embora os valores sejam divergentes dos valores obtidos pelos métodos analíticos. A avaliação das faces de fratura dos corpos de prova por microscopia eletrônica de varredura permitiu visualizar que nas regiões onde visualmente considerou-se que havia apenas fratura frágil, também haviam regiões típicas de fratura dúctil. Conclui-se que a metodologia mais indicada é aquela que considera a TTDF como a temperatura na qual a energia absorvida é a média dos patamares superior e inferior, pois é um método simples, de fácil reprodutibilidade e que melhor refletiu a tendência de comportamento do material nos diferentes graus de encruamento estudados.

Palavras-chave: Ensaio Charpy; TTDF; Fratura frágil; Fratura dúctil.

\section{INVESTIGATION OF METHODS FOR DBTT DETERMINATION BY USING CHARPY IMPACT TESTING}

\section{Abstract}

The purpose of this work was to define ASTM A-36 steel DBTT, presenting various pre-strain levels, after Charpy impact testing, by using several methodologies, evaluating its validity. When DBTT values were obtained from lateral expansion, it was not possible to notice any relation with pre-strain, neither when DBTT values were defined as the temperature where $50 \%$ of brittle fracture was determined, for both quantitative and qualitative methods of evaluation, although these values are different from analytical results. When fractures were evaluated by scanning electron microscopy, and it was possible to visualize that in the portions where, from visual analysis, it was considered that a brittle fracture occurs, there are also plastic deformation, which means that a ductile fracture also occurs. It was concluded that the most indicate methodology for DBTT determination is the one at which absorbed energy is the average between superior and inferior energy plateaus, since it is easy to be done and to be reproduced, and it is the one that better reflects material behavior for the adopted pre-strain levels.

Keywords: Charpy test; DBTT; Brittle fracture; Ductile fracture.

1 Mestre em Engenharia Mecânica, Centro Universitário da FEl, São Bernardo do Campo, SP, Brasil; katia_cris04@hotmail.com

2 Prof. Dr. do Departamento de Engenharia de Materiais, Centro Universitário da FEI, São Bernardo do Campo, SP, Brasil; rodrmagn@fei.edu.br.

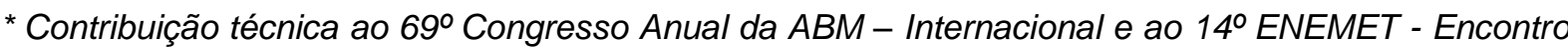
Nacional de Estudantes de Engenharia Metalúrgica, de Materiais e de Minas, 21 a 25 de julho de 2014, São Paulo, SP, Brasil.
} 


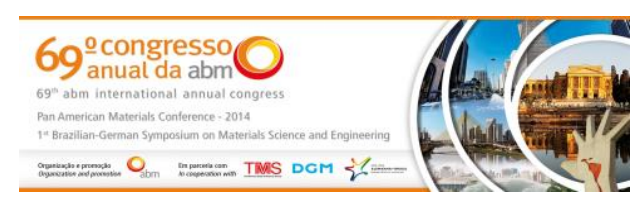

\section{INTRODUÇÃO}

O episódio dos navios de classe Liberty na $2^{\mathrm{a}}$ Guerra Mundial, quando navios atracados apresentavam fratura frágil sem razão aparente, trouxe à tona a necessidade de determinar uma temperatura abaixo da qual o comportamento à fratura do material se altera de dúctil para frágil. A essa temperatura se deu o nome de Temperatura de Transição Dúctil-Frágil (TTDF) dos materiais [1].

$\mathrm{Na}$ época da Segunda Guerra, entretanto, muito pouco sobre o assunto havia sido documentado. Dentre os ensaios disponíveis, o ensaio de impacto Charpy foi e continua sendo considerado aquele que mais se adequa às necessidades para 0 estudo deste assunto, atualmente sendo realizado conforme norma ASTM E23 [2].

Levantando-se os dados de absorção de energia de um material metálico de estrutura cristalina CCC, em diversas temperaturas, pode-se determinar a TTDF deste material. Usualmente, vê-se que ocorrem dois patamares de energia absorvida, chamados de "patamar inferior" e "patamar superior", e uma região entre eles, chamada de "zona de transição".

Lembrando que em temperaturas correspondentes ao patamar inferior de absorção de energia o material apresentará fratura predominantemente frágil por clivagem, e que em temperaturas correspondentes ao patamar superior de absorção de energia, o material apresentará fratura predominantemente dúctil, fica fácil entender que a TTDF poderá ser encontrada na região de transição da curva. Difícil tarefa, entretanto, é determiná-la, uma vez que se trata de uma temperatura de referência para a mudança de comportamento à fratura do material. Torna-se então necessário consolidar um critério adequado para definir a TTDF, comparando-se as metodologias citadas na norma ASTM E23 [2]: os métodos de avaliação visual das faces de fratura qualitativa e quantitativamente, utilizando os valores de energia absorvida ou ainda utilizando os dados de expansão lateral dos corpos de prova, sempre em função da temperatura.

Diante deste contexto, o objetivo deste trabalho é realizar a determinação da TTDF do aço ASTM A-36 [3] utilizando várias metodologias, e realizar um estudo comparativo entre elas, a fim de estabelecer qual delas é a melhor para este fim.

\section{MATERIAIS E MÉTODOS}

O material utilizado foi o aço ASTM A36 [3], com espessura de 12,7 mm, ao qual foram aplicados 2 níveis de pré-deformação (4,5\% e 8,6\%) em solicitação uniaxial em tração num equipamento servohidráulico MTS de $250 \mathrm{kN}$ de capacidade máxima, além do material em sua condição de entrega, resultando num total de 87 corpos de prova tipo A, conforme norma ASTM E23 [2]. Os corpos de prova foram ensaiados ao impacto a diferentes temperaturas conforme a mesma norma, que também descreve as diferentes metodologias utilizadas para definir a TTDF em cada condição do material. Foram realizados ensaios em 8 temperaturas, sendo que para cada temperatura e para cada condição de pré-deformação foram utilizados pelo menos 8 corpos-de-prova.

Desta forma, para cada corpo de prova foi possível obter as seguintes informações em função da temperatura, conforme indicação da norma ASTM E23 [2]:

1. Energia absorvida: valores obtidos pela leitura direta dos valores de energia indicados na máquina de ensaio de impacto no momento da realização do ensaio.

\footnotetext{
* Contribuição técnica ao $69^{\circ}$ Congresso Anual da ABM - Internacional e ao 14ํㅡㄹ ENEMET - Encontro Nacional de Estudantes de Engenharia Metalúrgica, de Materiais e de Minas, 21 a 25 de julho de 2014, São Paulo, SP, Brasil.
} 
2. Valores de expansão lateral: valores obtidos pela medição dos corpos de prova, em um projetor de perfis. A Figura 1 ilustra a metodologia de medição para obtenção dos dados:

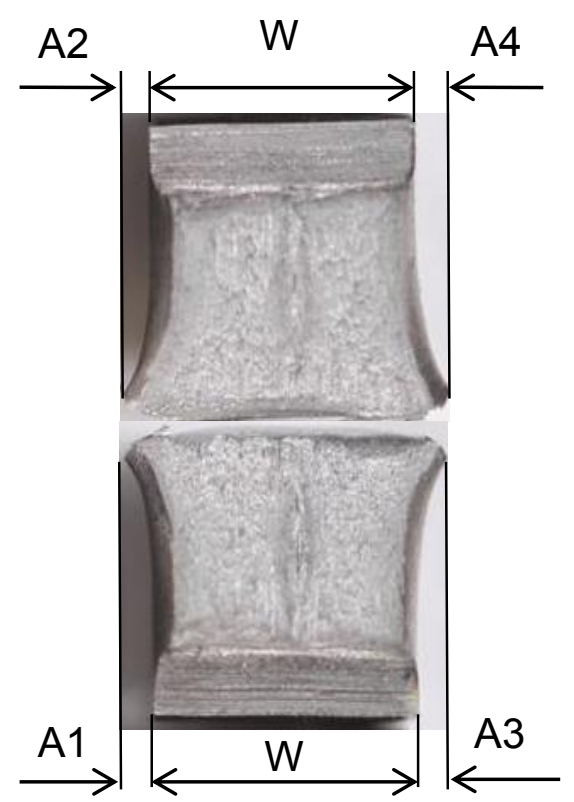

Figura 1 - Croqui das metades de um corpo de prova Charpy após ensaio, indicando as regiões de medição da expansão lateral do corpo de prova (cotas A1, A2, A3 e A4) e sua dimensão original (cotas W).

3. Porcentagem de fratura dúctil pelo método qualitativo: avaliação visual das faces de fratura dos corpos de prova e comparação com os registros de faces de fratura disponíveis na norma, apresentados na Figura 2:

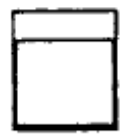

10

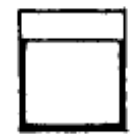

20

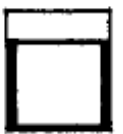

30

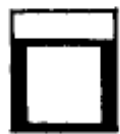

40

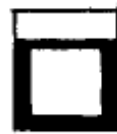

50

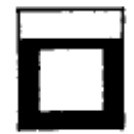

60

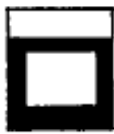

70

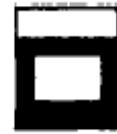

80

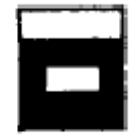

90

Figura 2 - Desenhos de referência para avaliação das faces de fratura do ensaio de impacto Charpy [2].

4. Porcentagem de fratura dúctil quantitativo: medição da região de fratura dúctil nas faces de fratura dos corpos de prova, conforme croqui da Figura 3, retirado da norma.

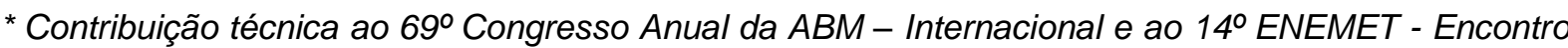
Nacional de Estudantes de Engenharia Metalúrgica, de Materiais e de Minas, 21 a 25 de julho de 2014, São Paulo, SP, Brasil.
} 

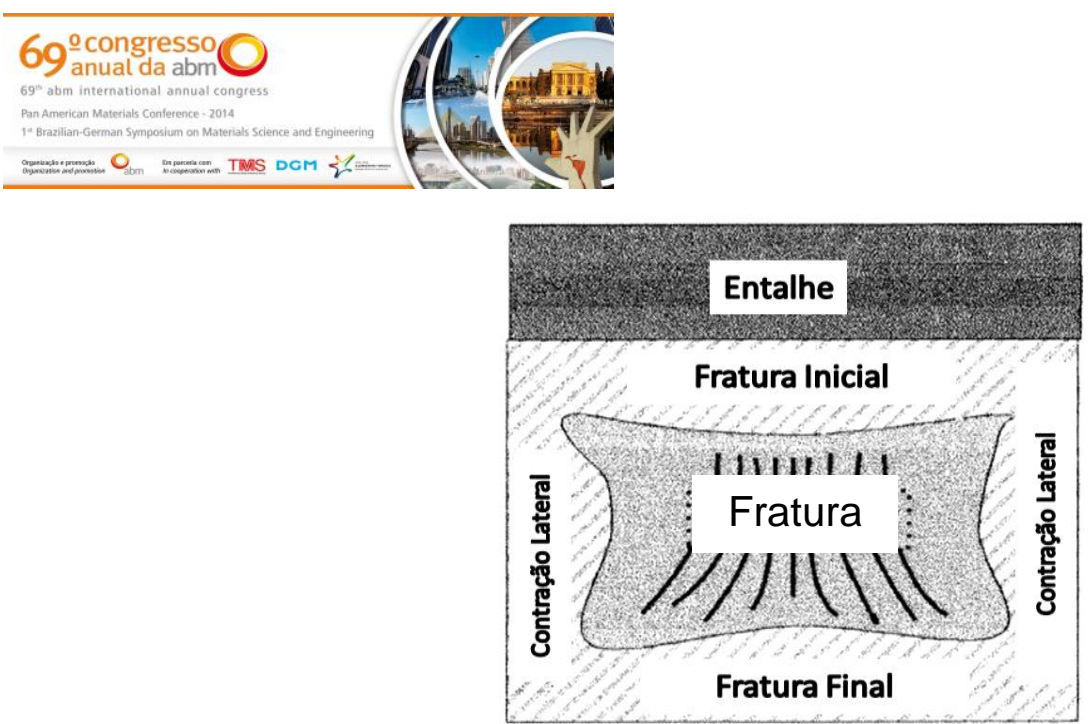

Figura 3 - Desenho esquemático de referência apresentado na norma ASTM E23 para avaliação da face de fratura do corpo de prova Charpy [2].

Os dados obtidos foram tratados pelo método da Tangente Hiperbólica, conforme descrito por Eircksonkirk e Shaikh [4] e o valor da TTDF foi estabelecido de acordo com as seguintes definições:

1. TTDF-mEn: Temperatura de Transição Dúctil-Frágil na qual ocorre a média das energias absorvidas nos patamares superior e inferior;

2. TTDF-mEL: Temperatura de Transição Dúctil-Frágil na qual ocorre a média das expansões laterais dos corpos de prova ensaiados ao impacto;

3. TTDF-50/50: Temperatura de Transição Dúctil-Frágil na qual ocorre $50 \%$ de fratura dúctil e $50 \%$ de fratura frágil;

4. TTDF-TDN: Temperatura de Transição Dúctil-Frágil na qual ocorre transição de ductilidade nula, ou seja, fratura $100 \%$ frágil;

5. TTDF-TFN: Temperatura de Transição Dúctil-Frágil na qual ocorre transição de fragilidade nula, ou seja, fratura $100 \%$ dúctil;

6. TTDF-20J: Temperatura de Transição Dúctil-Frágil na qual ocorre absorção de $20 \mathrm{~J}$ de energia.

Análise de Microscopia Eletrônica de Varredura (MEV) foi realizada nas superfícies de fratura para avaliação do micromecanismo de fratura dos corpos de prova.

\section{RESULTADOS E DISCUSSÃO}

As curvas obtidas pelo tratamento dos dados pelo método da Tangente Hiperbólica conforme descrito por Eircksonkirk e Shaikh [4] para o material nas 3 condições de pré-deformação do material, para cada critério utilizado, são apresentadas nas Figuras 4 a 7.

\footnotetext{
* Contribuição técnica ao 69ำ Congresso Anual da ABM - Internacional e ao 14ํㅡㄹ ENEMET - Encontro Nacional de Estudantes de Engenharia Metalúrgica, de Materiais e de Minas, 21 a 25 de julho de 2014, São Paulo, SP, Brasil.
} 

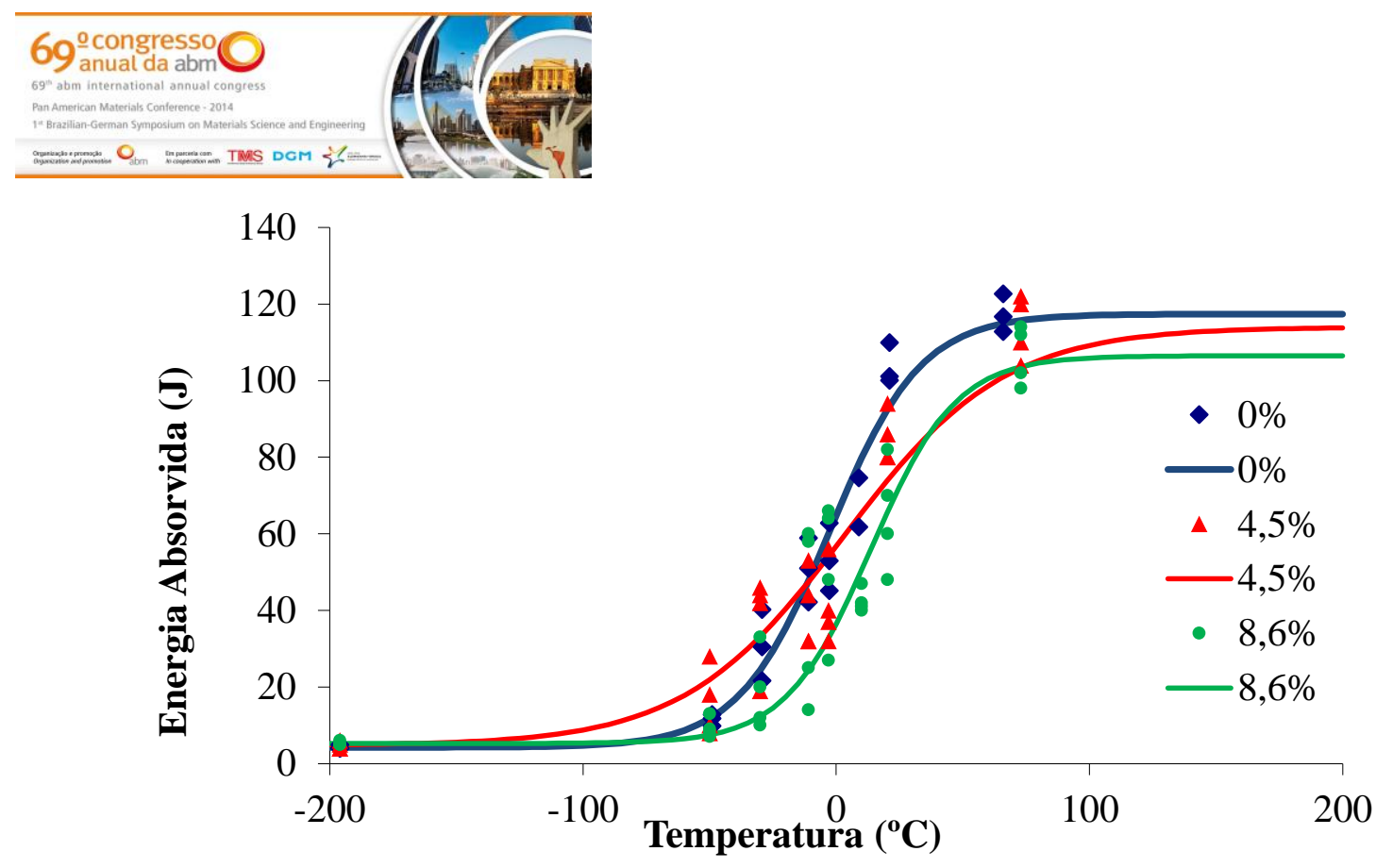

Figura 4 - Curvas de energia absorvida em função da temperatura ajustadas pelo método da Tangente Hiperbólica dos corpos de prova ensaiados nas 3 condições de pré-deformação.

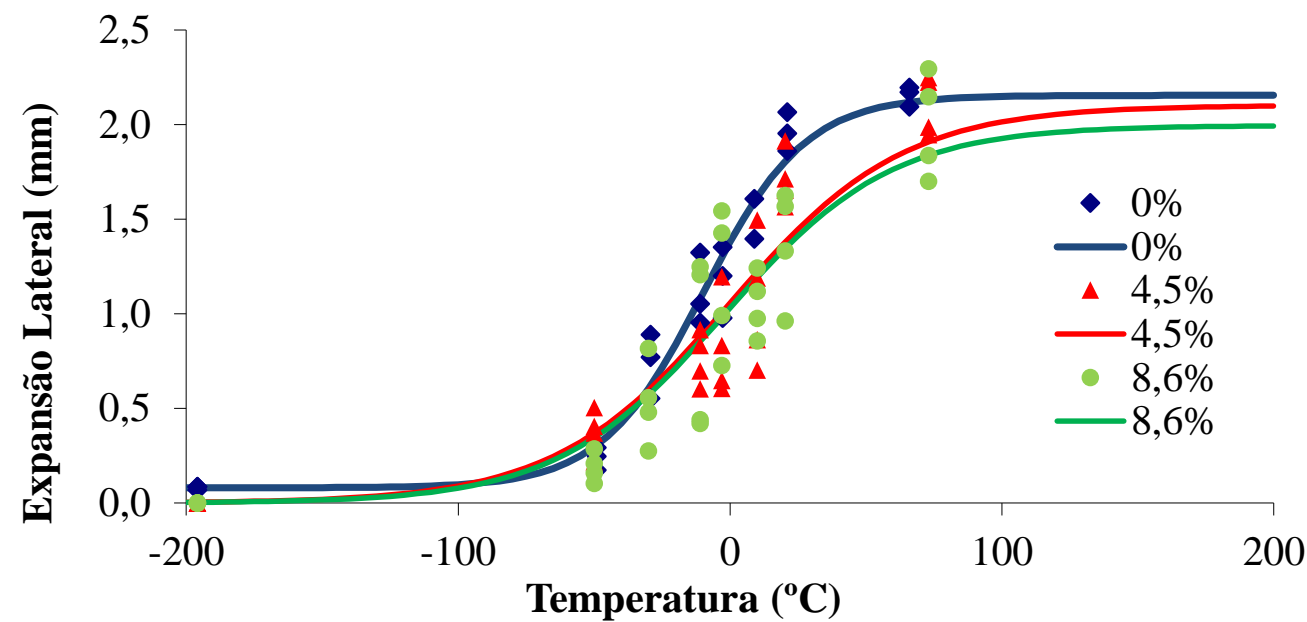

Figura 5 - Curvas de expansão lateral em função da temperatura ajustadas pelo método da Tangente Hiperbólica dos corpos de prova ensaiados nas 3 condições de deformação.

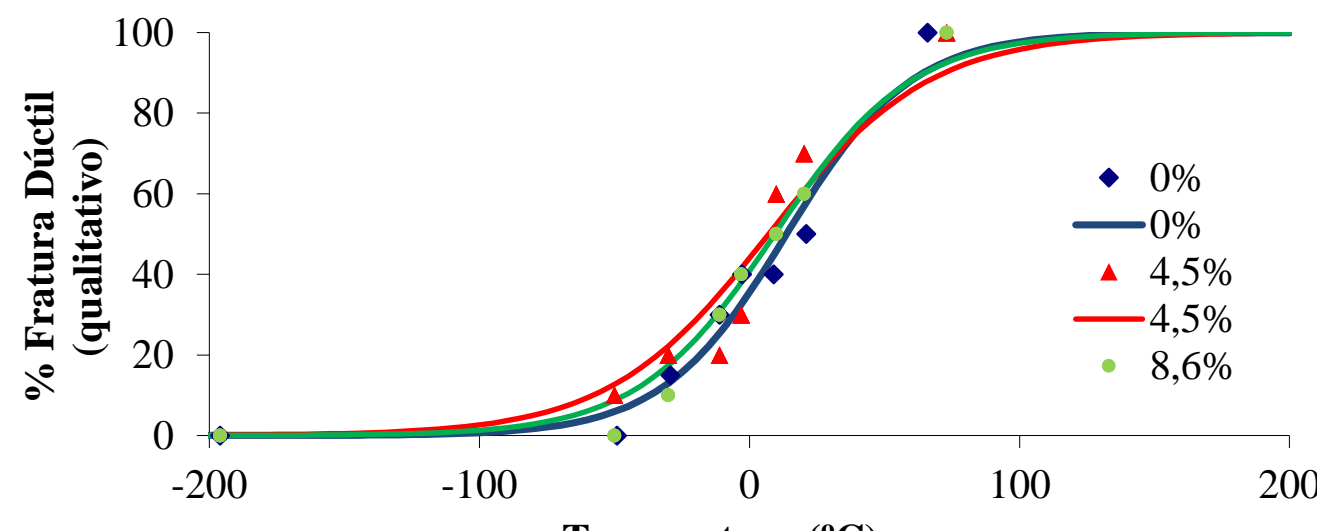

Temperatura $\left({ }^{\circ} \mathrm{C}\right)$

Figura 6 - Porcentagem de fratura dúctil (qualitativo) em função da temperatura ajustadas pelo método da Tangente Hiperbólica dos corpos de prova ensaiados nas 3 condições de deformação.

* Contribuição técnica ao 69 Congresso Anual da ABM - Internacional e ao 14ํㅡㄹ ENEMET - Encontro Nacional de Estudantes de Engenharia Metalúrgica, de Materiais e de Minas, 21 a 25 de julho de 2014, São Paulo, SP, Brasil. 

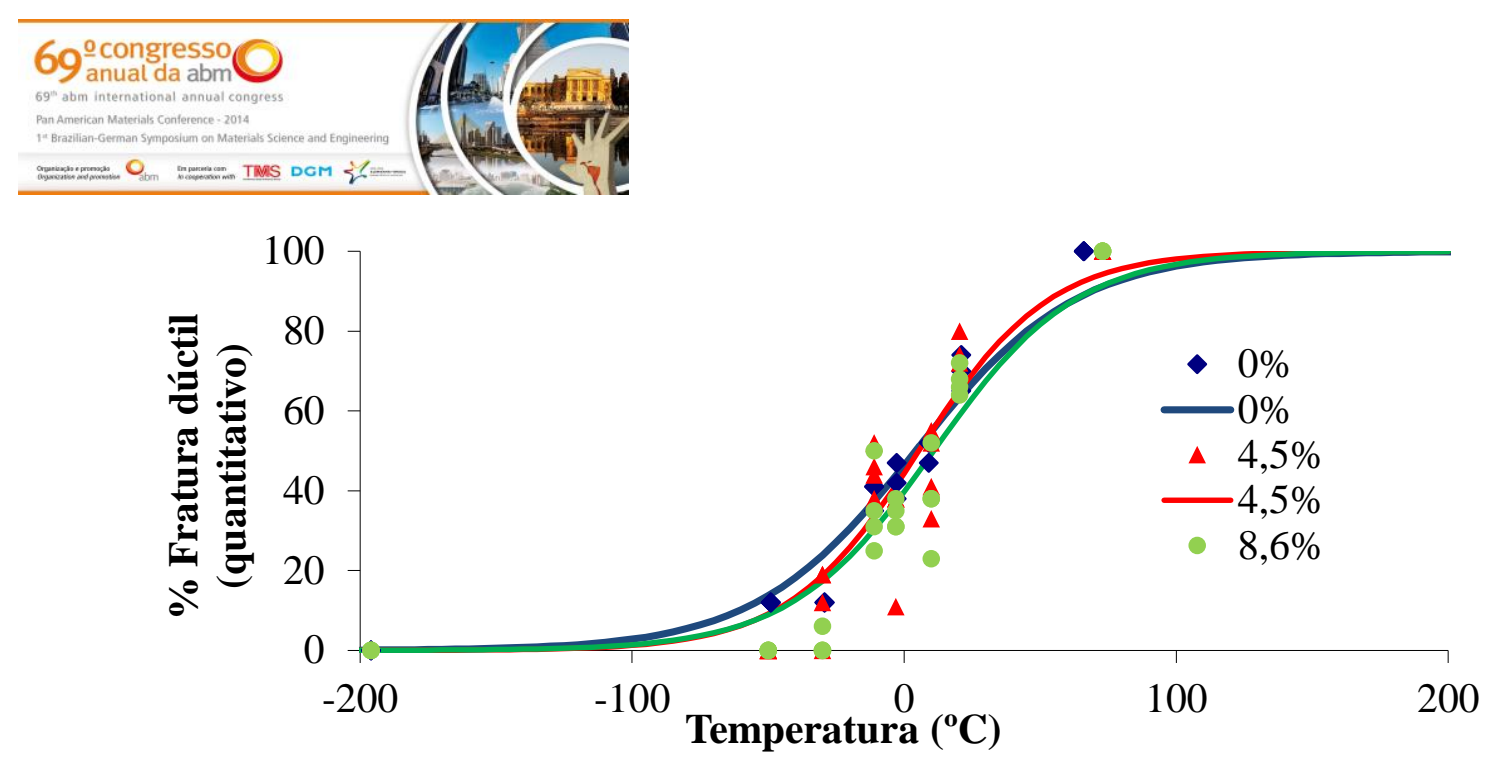

Figura 7 - Porcentagem de fratura dúctil (quantitativo) em função da temperatura ajustadas pelo método da Tangente Hiperbólica dos corpos de prova ensaiados nas 3 condições de deformação.

Avaliando-se as curvas de energia absorvida em função da temperatura (Figura 4), vê-se que, para os materiais com $4,5 \%$ e $8,6 \%$ de deformação, a região de transição vai de $-40^{\circ} \mathrm{C}$ a $40^{\circ} \mathrm{C}$ aproximadamente, enquanto que a região de transição para 0 material sem pré-deformação apresenta uma região de transição $-60^{\circ} \mathrm{C}$ até $100^{\circ} \mathrm{C}$, sendo portanto uma transição mais suave. Já nos gráficos de expansão lateral em função da temperatura, vê-se que a região de transição é mais estreita, ocorrendo num intervalo menor de temperaturas, principalmente para o material sem deformação, sendo que para os materiais com pré-deformação a transição ocorre no intervalo entre $-50^{\circ} \mathrm{C}$ e $50^{\circ} \mathrm{C}$. Estes valores se aproximam do intervalo de temperaturas da região de transição obtidos pela avaliação de porcentagem de fratura dúctil qualitativa, enquanto que pelo método de avaliação de porcentagem de fratura dúctil quantitativa o intervalo de temperaturas no qual a região de transição ocorre vai de $-50^{\circ} \mathrm{C}$ a $70^{\circ} \mathrm{C}$ aproximadamente.

Os valores de TTDF obtidos por cada método de avaliação, para cada nível de prédeformação encontram-se na Tabela 1.

Tabela 1 - Valores de TTDF $\left(e m{ }^{\circ} \mathrm{C}\right)$ obtidos para cada condição do material.

\begin{tabular}{c|c|c|c|c}
\cline { 3 - 5 } \multicolumn{2}{c}{ Critério } & \multicolumn{3}{c}{ Pré-deformação } \\
\hline \multirow{3}{*}{ Energia absorvida } & TTDF-20J & -38 & -50 & -18 \\
\cline { 2 - 5 } & TTDF-mEn & -2 & 3 & 14 \\
\cline { 2 - 5 } & TTDF-TFN & 35 & 68 & 82 \\
\cline { 2 - 5 } & TTDF-TDN & -40 & -60 & -58 \\
\hline \multirow{2}{*}{ Expansão lateral } & TTDF-mEL & $-9,7$ & $-0,4$ & $-2,0$ \\
\hline \multirow{2}{*}{ Porcentagem de fratura dúctil qualitativo } & TTDF-50/50 & 14 & 7 & 9 \\
\cline { 2 - 5 } & TTDF-TDN & -31 & -58 & -42 \\
\cline { 2 - 5 } & TTDF-TFN & 60 & 76 & 60 \\
\hline \multirow{2}{*}{ Porcentagem de fratura dúctil quantitativo } & TTDF-50/50 & 4 & 5 & 11 \\
\cline { 2 - 5 } & TTDF-TDN & -25 & -48 & -50 \\
\cline { 2 - 5 } & TTDF-TFN & 45 & 55 & 70 \\
\hline
\end{tabular}

Verifica-se que os valores obtidos quando se adota cada uma das diferentes definições para determinação da TTDF são diferentes entre si. O valor da TTDF-TFN é o maior deles, sendo portanto o mais conservador de todos, pois considera que a temperatura de transição é aquela na qual ainda não existe fratura por clivagem. Além disso, observa-se que os valores de TTDF-TFN obtidos pelo critério de

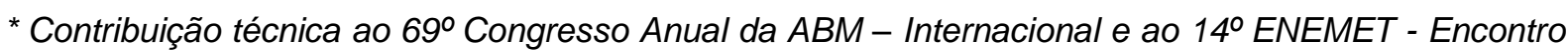
Nacional de Estudantes de Engenharia Metalúrgica, de Materiais e de Minas, 21 a 25 de julho de 2014, São Paulo, SP, Brasil. 
absorção de energia e pela porcentagem de fratura dúctil quantitativo aumentam quanto maior é a pré-deformação do material, mostrando uma tendência do comportamento do material, enquanto o mesmo não acontece pelo critério de fratura dúctil qualitativo.

Os valores de TTDF-50/50 obtidos pelos critérios de porcentagem de fratura dúctil qualitativo e quantitativo, apesar de ambos serem resultados da avaliação das faces de fratura dos corpos de prova, diferem entre si. Além disso, nenhum deles é capaz de determinar diferenças de TTDF em função da pré-deformação do material.

Quando os valores de TTDF-50/50 qualitativo e quantitativo são comparados também com os valores de TTDF-mEn e TTDF-mEL, já que todos poderiam estar relacionados a ocorrência de mesmas frações de fratura dútil e frágil, observa-se uma diferença ainda maior entre os resultados. Assim, para avaliar o micromecanismo de fratura, foram realizadas análises das faces de fratura por Microscopia Eletrônica de Varredura (MEV). Esta verificação teve por objetivo confirmar o micromecanismo de fratura observado visualmente nas faces de fratura dos corpos de prova ensaiados ao impacto Charpy nas diferentes temperaturas.

A Figura 8 traz imagem da face de fratura de um corpo de prova ensaiado a $66^{\circ} \mathrm{C}$, confirmando a presença de fratura $100 \%$ dúctil e também da face de fratura de um corpo de prova ensaiado a $-196^{\circ} \mathrm{C}$, que confirma a presença de fratura $100 \%$ frágil, conforme previsto.

Os corpos de prova ensaiados a $-2^{\circ} \mathrm{C}$ são a parte do material sem pré-deformação ensaiada a temperatura mais próxima das TTDF-mEn e TTDF-mEL, e cujas faces de fratura obtida pelo ensaio de impacto foram consideradas como apresentando $50 \%$ de fratura frágil e $50 \%$ de fratura dúctil, o que condiz com o comportamento que se espera do material na temperatura de transição. Diante dessas considerações, se torna interessante avaliar com mais atenção o micromecanismo de fratura destes corpos de prova por MEV.

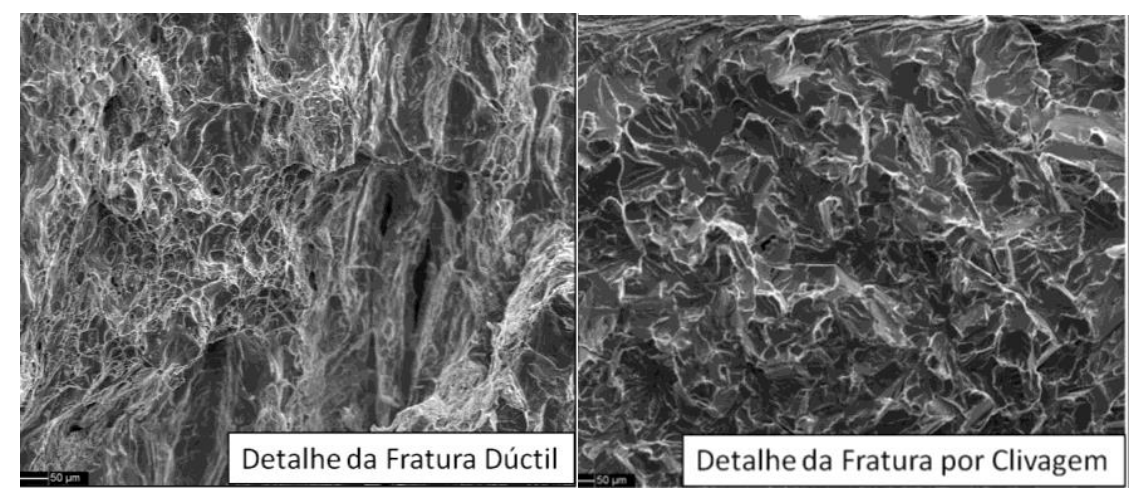

Figura 8 - Avaliação das faces de fratura dos corpos de prova ensaiados ao impacto a $66^{\circ} \mathrm{C}(\mathrm{a}$ esquerda) e a $-196^{\circ} \mathrm{C}$ (à direita), sem pré-deformação, por técnica de microscopia eletrônica de varredura.

A Figura 9 mostra em detalhe cada porção distinta da face de fratura, ou seja, onde visualmente se considerou que há fratura por clivagem, com aspecto brilhante, e fratura dúctil, que apresenta deformação plástica. Além disso, foi possível verificar que, apesar da confirmação do micromecanismo de fratura dúctil nas regiões das faces de fratura dos corpos de prova onde a deformação plástica do material podia ser visualmente determinada, e do micromecanismo de fratura por clivagem a menores temperaturas, a avaliação mostra que a verificação visual não representa com exatidão o micromecanismo pelo qual a fratura realmente ocorreu nas regiões

\footnotetext{
* Contribuição técnica ao 69ำ Congresso Anual da ABM - Internacional e ao 14ํㅡㄹ ENEMET - Encontro Nacional de Estudantes de Engenharia Metalúrgica, de Materiais e de Minas, 21 a 25 de julho de 2014, São Paulo, SP, Brasil.
} 
de fratura brilhante, que deveriam apresentar exclusivamente o micromecanismo de fratura por clivagem. Quando foram avaliados corpos de prova ensaiados a temperaturas dentro da região de transição, foi possível verificar regiões de deformação plástica dentro da região de fratura plana (ou por clivagem), que são indicadas por setas na Figura 10. A seta contínua indica uma região de fratura dúctil, onde se pode visualizar os alvéolos típicos de fratura que ocorre por este micromecanismo. Já a seta tracejada indica uma região de fratura por clivagem.

Diante dessas análises, pode-se confirmar, portanto, que a avaliação visual não traz resultados precisos quanto ao comportamento do material ao impacto, e com isso entende-se porque o valor de TTDF-50/50 qualitativo ou quantitativo difere tanto dos dados de TTDF-mEn e TTDF-EL.

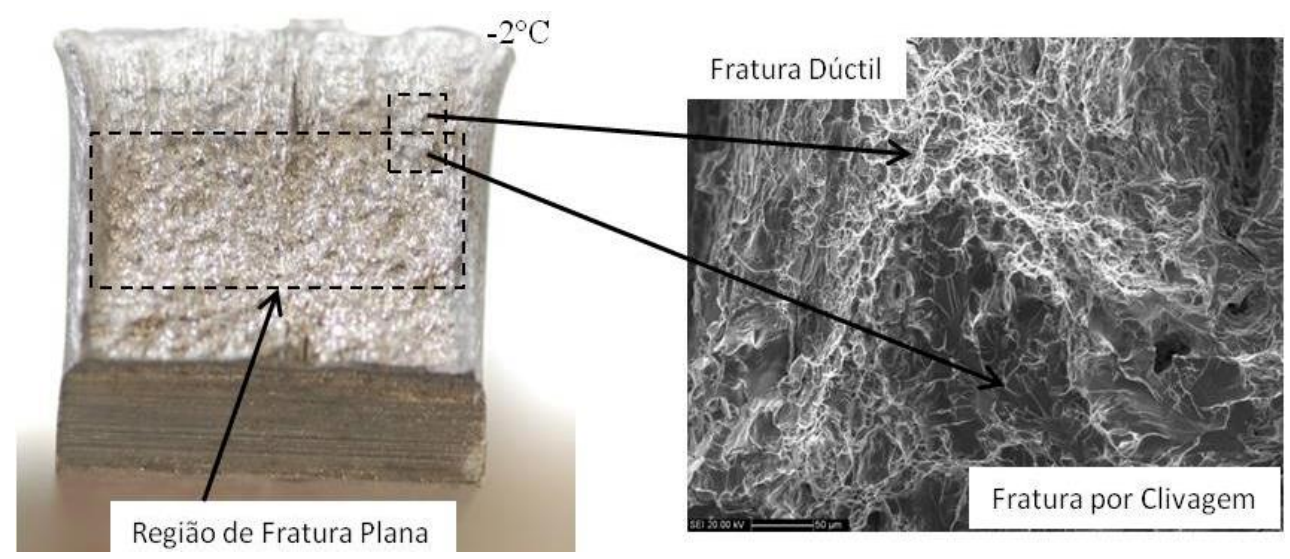

Figura 9 - Avaliação da face de fratura de um corpo de prova ensaiado ao impacto a $-2^{\circ} \mathrm{C}$, sem pré deformação. A esquerda, registro fotográfico, e a direita, registro por MEV.

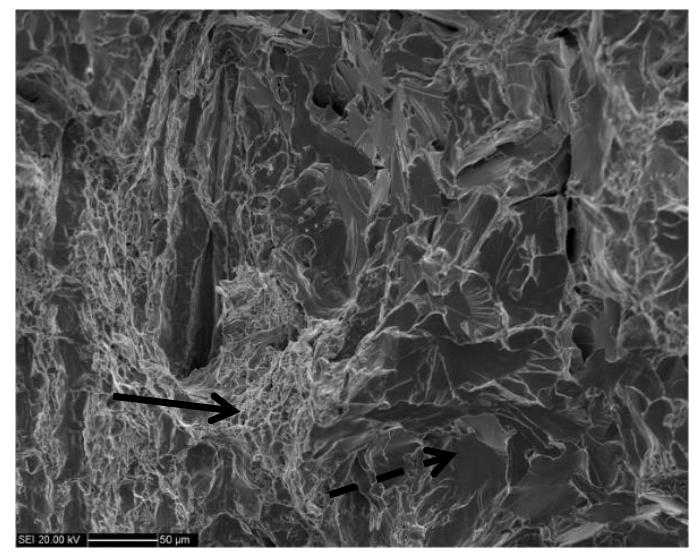

Figura 10 - Avaliação da face de fratura de um corpo de prova ensaiado sem pré-deformação, na região da fratura visualmente avaliada como fratura por clivagem. A seta contínua indica uma região de fratura dúctil, enquanto a seta tracejada indica uma região de fratura por clivagem.

Voltando à discussão dos resultados gerais, notam-se discrepâncias entre os valores de TTDF-TDN e TTDF-20J obtidos para o material sem pré-deformação. Assim como comentado por Tanguy et al. [5], o valor da TTDF-TDN (qualitativo ou quantitativo) não deveria ser maior que o valor da TTDF-20J, já que o material absorve mais energia quanto maior for a temperatura de ensaio. Vê-se que este resultado não faz sentido, pois quando o material absorve 20J de energia ele já se encontra em sua região de transição (Figuras 4 a 7), conforme se pode verificar no

\footnotetext{
* Contribuição técnica ao 69 Congresso Anual da ABM - Internacional e ao 14ํㅡㄹ ENEMET - Encontro Nacional de Estudantes de Engenharia Metalúrgica, de Materiais e de Minas, 21 a 25 de julho de 2014, São Paulo, SP, Brasil.
} 
gráfico de energia absorvida em função da temperatura, e portanto apresenta alguma fratura dúctil. Não é possível, então, dizer que a uma temperatura mais alta ocorreria a condição de ductilidade nula, como seria esperado pela definição de TTDF-TDN. Sabendo que os dados de TTDF-TDN, qualitativo e quantitativo, são bastante subjetivos, pois são obtidos exclusivamente pela observação macroscópica da face de fratura do corpo de prova, conforme já comentado, e o valor de TTDF-20J é obtido indiretamente a partir dos dados aproximados por uma equação de Tangente Hiperbólica determinada a partir dos dados de energia absorvida no momento do ensaio, fica evidente que a confiabilidade deste valor é superior, sendo, portanto, o critério mais indicado para utilização entre estes outros.

Avaliando os valores de TTDF-TDN obtidos para os critérios de energia e de porcentagem de fratura dúctil qualitativo e quantitativo, observa-se que apenas os valores obtidos por este último critério representam o comportamento do material com relação à sua pré-deformação, pois os valores se alteram juntamente com a mudança no valor da pré-deformação. Além disso, cabe comentar a diferença significativa dentre os valores obtidos, embora todos tenham sido obtidos pela extrapolação das curvas de ajuste pelo método da Tangente Hiperbólica. Da mesma forma, os valores de TTDF-TFN obtidos para os critérios de energia e de porcentagem de fratura dúctil qualitativo e quantitativo são divergentes, sendo que apenas os valores obtidos para o critério quantitativo apresentam algum indício sobre o comportamento do material.

\section{CONCLUSÕES}

Neste trabalho, as diferentes definições para a TTDF foram apresentadas e utilizadas para a avaliação do comportamento ao impacto do aço ASTM A36 com diferentes graus de pré-deformação.

Verificou-se que apenas os valores obtidos para TTDF-mEn, TTDF-TFN obtido pelos critérios de energia e de porcentagem de fratura dúctil quantitativo, e TTDF-TDN também obtido por este critério trazem algum indício quanto ao comportamento do material, pois mostram variação contínua com o aumento da pré-deformação do material.

Por sua vez, os valores de TTDF-20J e TTDF-TDN apresentam valores que não fazem sentido. Entretanto, esta característica variou entre as diferentes condições de pré-deformação do material. Para todos eles, contudo, o valor da TTDF-TFN é o maior dentre eles, sendo portanto o mais conservador.

Por outro lado, os valores obtidos para a TTDF-50/50 variaram muito em relação às TTDF-mEn e TTDF-EL, quando se esperava que também apresentassem valores próximos, considerando que a porcentagem de fratura dúctil variaria de maneira similar à expansão lateral em função da temperatura de ensaio. Pela avaliação das faces de fratura dos corpos de prova por microscopia eletrônica de varredura, foi possível visualizar que nos corpos de prova ensaiados na zona de transição há regiões onde, por avaliação visual considerou-se que havia fratura por clivagem, mas nestas também há regiões com alvéolos resultantes de deformação plástica do material, típicos de fratura dúctil. Sendo assim, a determinação da TTDF pelo método da porcentagem de fratura dúctil ou por clivagem fica comprometida, pois por ser um método macroscópico, mesmo que visualmente se julgue que uma face de fratura apresenta $50 \%$ de fratura por clivagem e $50 \%$ de fratura dúctil ou mesmo avalie-se $100 \%$ de fratura por clivagem, ficou confirmado que esta avaliação não é completamente verdadeira.

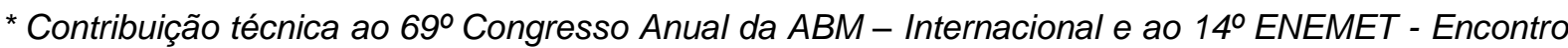
Nacional de Estudantes de Engenharia Metalúrgica, de Materiais e de Minas, 21 a 25 de julho de 2014, São Paulo, SP, Brasil.
} 
Considerando todos os resultados obtidos e comentados acima, pode-se finalmente afirmar que o valor de TTDF-mEn obtido pelo critério de absorção de energia é o método mais adequado para determinar a TTDF de um material com prédeformação até $8,6 \%$, por ser de simples execução, consequentemente com pequeno índice de erros intrínsecos do método, uma vez que os dados são obtidos pela leitura direta dos valores de energia absorvida na escala da máquina de ensaio, e por representar o comportamento do material.

\section{REFERÊNCIAS}

1 Garcia A, Spim JA, Santos CA. Ensaio dos materiais. Rio de Janeiro: LTC, 2008.

2 American Society for Testing and Materials. ASTM E23: Standard Test Methods for Notched Bar Impact Testing of Metallic Materials. Philadelfia; 2012.

3 American Society for Testing and Materials. ASTM A3: Standard Specification for Carbon Structural Steel. Philadelfia; 2012.

4 Eircksonkirk M, Shaikh A. Insights and observations arising from curve-fitting the Charpy V-Notch and tensile data contained within the United Stats' light water reactor surveillance database. Proceedings of PVP2008-61650 ASME 2008 Pressure Vassels and Piping Division Conference. Chicago-Illinois, USA, 2008.

5 Tanguy B, Besson J, Piques R, Pineou A. Ductile to brittle transition of an A508 steel characterized by charpy impact test part I: experimental results. EvryCedex, 2007.

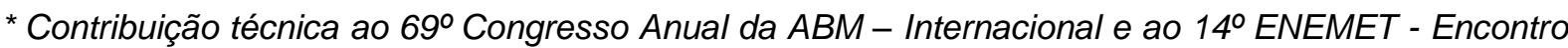
Nacional de Estudantes de Engenharia Metalúrgica, de Materiais e de Minas, 21 a 25 de julho de 2014, São Paulo, SP, Brasil. 